\title{
3D Printing of Pharmaceutical Drug Delivery Systems
}

\author{
Diogo José Horst* \\ Production Engineering Department, Federal University of Technology, Brazil
}

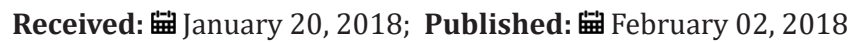

*Corresponding author: Diogo José Horst, Production Engineering Department, Federal University of Technology, Paraná, Brazil, Tel: +55(42)3220-4800; Email: diogohorst@gmail.com

\begin{abstract}
Three-dimensional printing (3DP) enables the development of diverse geometries through computer aided design using different techniques and materials for desired applications such as pharmaceutical drug delivery medicine. The FDA approval (2015) of printed-medicine opens up an unprecedented opportunity for the discovery of new compounds and technologies for the pharmaceutical industry development. This report shows some advantages, limitations, challenges and perspectives in concerning to 3DP of pharmaceutical grade formulations and polymers used for drug delivery systems.
\end{abstract}

\section{Introduction}

Drug delivery refers to approaches, systems, technologies and formulations for transporting a pharmaceutical compound in the body as needed to safely achieve its desired therapeutic effect. The concept of drug delivery has greatly evolved over the years from immediate-release oral dosage forms to targeted-release drug delivery systems. Indeed, the necessity of controlling the drug release profile to modulate the absorption, the distribution, the metabolization and the elimination of the drug rapidly appeared as a key factor for improving product efficacy and safety as well as to increase the compliance of the patients [1]. In the drug delivery area, versatile therapeutic systems intended to yield customized combinations of drugs, drug doses and release kinetics have drawn increasing attention, especially because of the advantages that personalized pharmaceutical treatments would offer [2].

Three dimensional printing (3DP) technology is a novel technique for rapid prototyping, which constructs solid objects by deposition of several layers in sequence. The introduction and application of 3D printing have promoted enormous innovations in many diverse fields, including aerospace industry, architecture, tissue engineer, biomedical research and pharmacy. It seems that 3D printing technology will lead a new epoch of the next industrial revolution based on its versatility and diversity. Along with development and progress in science and technology, the 3D printing technology gets mature enough so that anyone can apply it with open-source software at a relative lower material cost [3]. The recent introduction of the first FDA approved 3D-printed drug has fuelled interest in 3D printing technology, which is set to revolutionize healthcare. Since its initial use, this rapid prototyping (RP) technology has evolved to such an extent that it is currently being used in a wide range of applications including in tissue engineering, dentistry, construction, automotive and aerospace. However, in the pharmaceutical industry this technology is still in its infancy and it's potential yet to be fully explored [4].

3DP is gaining increasing attention in pharmaceutical formulation development as an effective strategy to overcome some challenges of conventional pharmaceutical unit operations. For instance, the conventional manufacturing unit operation involving milling, mixing, granulation and compression can result in disparate qualities of the final products with respect to drug loading, drug release, drug stability and pharmaceutical dosage form stability $[5,6]$. 3D printing technology has enabled unprecedented flexibility in the design and manufacturing of complex objects, which can be utilized in personalized and programmable medicine [7]. In this report are shown some advantages, limitations, challenges and perspectives of $3 \mathrm{D}$ printing in the elaboration of drug delivery systems.

\section{Advantages and Limitations}

Various techniques for 3D printing, such as fused deposition modeling (FDM), binder deposition, inkjet printing, material jetting, powder bed fusion, photopolymerization, pen-based 3D printing and molding, have been reported in the literature $[8,9]$. Fused 
Deposition Modeling (FDM) 3D printing has been recently attracted increasing research efforts towards the production of personalized solid oral formulations. However, commercially available FDM printers are extremely limited with regards to the materials that can be processed to few types of thermoplastic polymers, which often may not be pharmaceutically approved materials nor ideal for optimizing dosage form performance of poor soluble compounds
[10]. Such a technique holds huge potential for the manufacturing of pharmaceutical products and is currently under extensive investigation. Challenges in this field are mainly related to the paucity of adequate filaments composed of pharmaceutical grade materials, which are needed for feeding the FDM equipment [11] (Figure 1).

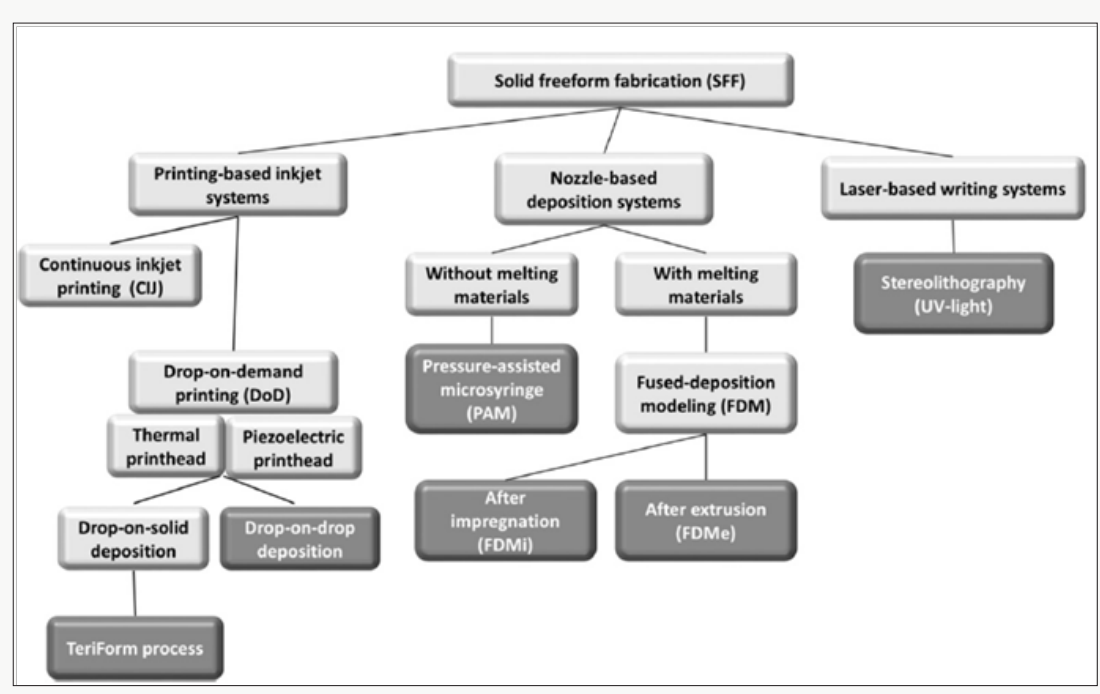

Figure 1: Schematic view of the different 3DP techniques used to fabricate drug delivery systems.

Source [12] From the many types of 3DP available, these matrices, it is possible in principle to fabricate pre-wetted, stereolithographic (SLA) printing offers the unique advantage drug-loaded hydrogels and devices [13]. of being able to fabricate objects by cross-linking resins to form networked polymer matrices. Because water can be entrapped in

Table 1 shows some 3DP technologies and pharmaceutical formulations for drug delivery.

Table 1: Current 3DP technologies and pharmaceutical formulations for drug delivery.

\begin{tabular}{|c|c|c|c|}
\hline Type of 3D process/technique & Dosage form & Active ingredient/polymer & Author \\
\hline Stereolithography (SLA) & Hydrogel & $\begin{array}{l}\text { ibuprofen, riboflavin, polyethylene } \\
\text { glycol, diacrylate }\end{array}$ & Martinez et al. [12] \\
\hline FDM 3D printing & Tablet & $\begin{array}{c}\text { felodipine, PEG, PEO, Tween 80, } \\
\text { Eudragit EPO }\end{array}$ & Alhijjaj et al. [10] \\
\hline UV inkjet 3D printed & Tablet & $\begin{array}{c}\text { ropinirole, cross-linked } \\
\text { poly(ethylene glycol diacrylate) } \\
\text { (PEGDA) }\end{array}$ & Clark et al. [22] \\
\hline $\begin{array}{l}\text { semi-solid extrusion 3D printing } \\
\text { technique in combination with UV- } \\
\text { LED crosslinking }\end{array}$ & Tablet & $\begin{array}{c}\text { prednisolone, } \\
\text { polydimethylsiloxan } \\
\text { (PDMS) }\end{array}$ & Hollander et al. [30] \\
\hline (FDM) and (SLA) & $\begin{array}{l}\text { model of a nose adapted to the } \\
\text { morphology of an individual }\end{array}$ & $\begin{array}{l}\text { FPLA-salicylic acid and PCL- } \\
\text { salicylic acid }\end{array}$ & Goyanes et al. [28] \\
\hline FDM & Tablet & haloperidol & Solanki et al. [32] \\
\hline Thermal Inkjet (TIJ) Printing & Solid dosage forms & rasagiline mesylate & Genina et al. [24] \\
\hline $\begin{array}{l}\text { (FDM) and Hot Melt Extrusion } \\
\text { (HME) }\end{array}$ & Tablet & $\begin{array}{l}\text { domperidone, hydroxypropyl } \\
\text { cellulose (HPC) }\end{array}$ & Chai et al. [23] \\
\hline FDM & Nanocapsules & $\begin{array}{c}\text { deflazacort, } \\
\text { poly( } \varepsilon \text {-caprolactone) }(\mathrm{PCL})\end{array}$ & Beck et al. [20] \\
\hline FDM and HME & Compartmentalized shells & rifampicin (RIF) and isoniazid (ISO) & Genina et al. [25] \\
\hline FDM & Tablet & Hydrochlorothiazide & Sadia et al. [31] \\
\hline
\end{tabular}




\begin{tabular}{|c|c|c|c|}
\hline 3D printed & Biodegradable patch & $\begin{array}{c}\text { poly(lactide-co-glycolide), } \\
\text { polycaprolactone, and } \\
\text { 5-fluorouracil }\end{array}$ & Yi et al. [33] \\
\hline FDM and HME & Subcutaneous rods & $\begin{array}{c}\text { indomethacin, ethylene vinyl } \\
\text { acetate (EVA) copolymers }\end{array}$ & Genina et al. [26] \\
\hline FMD and HME & $\begin{array}{c}\text { Three-compartment hollow } \\
\text { cylinder } \\
\text { polymer polyvinyl alcohol (PVA), } \\
\text { mannitol and hydrochlorothiazide } \\
\text { (HCTZ), polylactic acid (PLA) }\end{array}$ & GGioumouxouzis et al. [27] \\
\hline FDM & Tablet & $\begin{array}{c}\text { nitrofurantoin, polylactic acid and } \\
\text { hydroxypropyl methylcellulose }\end{array}$ & Boetker et al. [21] \\
\hline FDM and HME & $\begin{array}{c}\text { indomethacin, } \\
\text { poly( } \varepsilon \text {-caprolactone) }\end{array}$ & Hollander et al. [30] \\
\hline (HME) with 3D printing (3DP) & $\begin{array}{c}\text { 3D-printed-cube, pyramid, } \\
\text { cylinder, sphere and torus }\end{array}$ & $\begin{array}{c}\text { paracetamol loaded filaments of } \\
\text { polyvinyl alcohol }\end{array}$ & Goyanes et al. [29] \\
\hline
\end{tabular}

More information in concerning to these technologies and pharmacology is present in the studies of Jassim-Jaboori \& Oyewumi (14), Konta et al. [15], and Mauvi et al. [16].

\section{Challenges and Perspectives}

The technological advancements in the pharmaceutical field are constantly improving and provide various possibilities for meeting the needs of personalized drug therapy. The three-dimensional (3D) printing technology has endless potential in the fabrication of patient-specific drug delivery devices (DDD) and dosage forms as the technological development is progressing. Moreover, the rapidly evolving research on 3D printed DDD has enabled us to determine several challenges related to the manufacturing and marketing of personalized drug delivery systems. The 3D printing has enabled the fabrication of prototypes of DDD with varying complexity and shows that customization of drug products is possible. There is potential to improve patient-specific drug therapies of the future using printing technologies. The technological advancements, new scientific concepts, interdisciplinary work and defined regulatory guidelines will continue to support and strengthen the prospects of 3D printing as an option in the manufacture of medical products [17]. Three-dimensional printing (3DP) is a unique prototyping technology that has advanced over the past 35 years and has the great potential to revolutionize the field of drug delivery with its inherent advantages of customizability and the ability to fabricate complex solid dosage forms with high accuracy and precision. 3DP can fabricate solid dosage forms with variable densities and diffusivities, complex internal geometries, multiple drugs and excipients. 3DP can successfully address the issues relating to the drug delivery of poorly water-soluble drugs, peptides, potent drugs and the release of multi-drugs, etc. However, there are some problems that restrict the applications of 3DP in commercial market, such as the selections of suitable binders, excipients and the pharmaco-technical properties of final products. Further advancement in process performance is required to overcome these issues where 3DP technology can be successfully combined with novel drug delivery system (NDDS) [18].
3D printing encompasses a range of differing techniques, each involving advantages and open issues. Particularly, solidification of powder, extrusion, and stereo lithography have been applied to the manufacturing of drug products. The main challenge to their exploitation for personalized pharmacologic therapy is likely to be related to the regulatory issues involved and to implementation of production models that may allow to efficiently turn the therapeutic needs of individual patients into small batches of appropriate drug products meeting preset quality requirements [19].

Three-dimensional printing has become a useful and potential tool for the pharmaceutical sector, leading to personalized medicine focused on the patients' needs. It offers numerous advantages, such as increasing the cost efficiency and the manufacturing speed, since a rapid prototyping (RP) can be done in a matter of minutes. However, there is still a significant barrier to ensure that $3 \mathrm{D}$ printed medicines have the same efficacy, safety, and stability as the pharmaceuticals conventionally manufactured by the Pharmaceutical Industry. Regarding the establishment of guidelines, laws, quality systems and safety of use and consumption of 3D printed medicines, it is a great challenge for the regulatory authorities entailing great obstacles, given the traditional requirements by the pharmaceutical sector [13].

The use of various types of printing technologies offer potential solutions for personalized medicine and tailored dosage forms to meet the needs of individual treatments of the future. Many types of scenario for printed dosage form exist and the concepts include, on the simplest level, accurately deposited doses of drug substances. In addition, computer design allows endless opportunities to create suitable geometries with tailored functionality and different levels of complexity to control the release properties of one or multiple drug substances. It will take some time to convert these technological developments in printing to better treatments for patients, because challenges exist. However, printing technologies are developing fast and have the potential to allow the use of versatile materials to manufacture sophisticated drug-delivery systems and bio functional constructs for personalized treatments [20]. 
3D printing technology can handle complex internal structure such as internal walls, hollow channels, porosity, multiple material regions and multiple drug distributions. This is a feature traditional pharmaceutical manufacturing processes do not share, which ensures feasibility of realizing rapid release, sustained release, controlled release, multiple drug delivery system and personalized medicine based on structure design [21]. Indeed, drug delivery from 3-dimensional (3D) structures is a rapidly growing area of research. It is essential to achieve structures wherein drug stability is ensured, the drug loading capacity is appropriate and the desired controlled release profile can be attained. Attention must also be paid to the development of appropriate fabrication machinery that allows 3D drug delivery systems (DDS) to be produced in a simple, reliable and reproducible manner [22].

\section{Findings}

It is evidenced that through its versatility, speed of production and precision, the use of three-dimensional printing for the elaboration and distribution of controlled drugs plays a key role in the current pharmaceutical industry, considering that drugs can be designed according to the patient's need. The fused deposition modeling (FDM) technique and hot melt extrusion (HME) of filaments for 3DP still excels in relation to the other printing techniques, such as binder deposition, inkjet printing, material jetting, powder bed fusion, photopolymerization, pen-based 3D, printing and molding have been gaining more and more space. The use of 3DP in pharmaceutical formulation development is an effective strategy to overcome challenges of conventional pharmaceutical unit operations, since the conventional manufacturing operation can result in disparate qualities of the final products with respect to drug loading, drug release, drug stability and pharmaceutical dosage form stability. 3DP offers significant potential benefits in the field of drug delivery and pharmaceutical/medical device manufacture.

\section{References}

1. Goole J, Amighi K (2016) 3D printing in pharmaceutics: A new tool for designing customized drug delivery systems. Int J of Pharm 499: 376394.

2. Maroni A, Melocchi A, Parietti F, Foppoli A, Zema L, et al. (2017) 3D printed multi-compartment capsular devices for two-pulse oral drug delivery. J Cont Rel 268: 10-18.

3. Li Q Guan X, Cui M, Zhu Z, Chen K, et al. (2018) Preparation and investigation of novel gastro-floating tablets with 3D extrusion-based printing. Int J of Pharm 535: 325-332.

4. Alhnam MA, Okwuosa TC, Sadia M, Wan K-W, Ahmed W, et al. (2016) Emergence of 3D Printed Dosage Forms: Opportunities and Challenges. Pharm Res 33(8): 1817-1832.

5. Ursan ID, Chiu L, Pierce A (2013) Three-dimensional drug printing: a structured review. J Am Pharm Assoc 53: 136-144.

6. Jassim-Jaboori AH, Oyewumi MO (2015) 3D Printing Technology in Pharmaceutical Drug Delivery: Prospects and Challenges. J Biomol Res Ther 4(4): 1-3.
7. Larush L, Kaner I, Fluksman A, Tamsud A, Pawar AA, et al. 3D printing of responsive hydrogels for drug-delivery systems. J of $3 \mathrm{~d}$ Printing in Medicine 1(4).

8. Norman J, Madurawe RD, Moore CM, Khan MA, Khairuzzaman A (2017) A new chapter in pharmaceutical manufacturing: 3D-printed drug products. Adv Drug Deliv Rev 108: 39-50.

9. Ligon SC, Liska R, Stampfl J, Gurr M, Mülhaupt R (2017) Polymers for 3D printing and customized additive manufacturing. Chem Rev 117(15): 10212-10290.

10. Alhijjaj M, Belton P, Qi S. An investigation into the use of polymer blends to improve the printability of and regulate drug release from pharmaceutical solid dispersions prepared via fused deposition modeling (FDM) 3D printing. Eur J of Pharm and Biopharm 108: 111125.

11. Melocchi A, Parietti F, Maroni A, Foppoli A, Gazzaniga A, et al. (2016) Hot-melt extruded filaments based on pharmaceutical grade polymers for 3D printing by fused deposition modeling. Int J of Pharm 509(1-2): 255-263.

12. Martinez PR, Goyanes A, Basit AW, Gaisford S (2017) Fabrication of drugloaded hydrogels with stereo lithographic $3 \mathrm{D}$ printing. Int J of Pharm 532(1): 313-317.

13. Konta AA, García-Piña M, Serrano DR (2017) Personalised 3D Printed Medicines: Which Techniques and Polymers Are More Successful? Bio engineering 4(79).

14. Maulvi FA, Shah MJ, Solanki BS, Patel AS, Soni TG, et al. (2017) Application of 3D Printing Technology in the Development of Novel Drug Delivery Systems. Int J Drug Dev \& Res 9: 44-49.

15. Palo M, Hollander J, Suominem J, Yliruusi J, Sandler N (2017) 3D printed drug delivery devices: perspectives and technical challenges. Expert Rev Med Devices 14(9): 685-696.

16.Zema L, Melocchi A, Maroni A, Gazzaniga A (2017) Three-Dimensional Printing of Medicinal Products and the Challenge of Personalized Therapy. J of Pharm Sci 106(7): 1697-1705.

17. Sandler N, Preis M (2016) Printed Drug-Delivery Systems for Improved Patient Treatment. Trends Pharmacol Sci 37(12): 1070-1080.

18. Moulton SE, Wallace GG (2014) 3-dimensional (3D) fabricated polymer based drug delivery systems. J of Cont Rel 193: 27-34.

19. Aprecia Pharmacuticals (2015) FDA Approves The First 3d Printed Drug Product, Aprecia Introduces its First Product Using the ZipDose ${ }^{\circledR}$ Formulation Platform for the Treatment of Epilepsy

20. Beck RCR, Chaves PS, Goyanes A, Vucosavljevic B, Buanz A, et al. (2017) 3D printed tablets loaded with polymeric nanocapsules: An innovative approach to produce customized drug delivery systems. Int J of Pharmaceutics 528(1-2): 268-279.

21. Boetker J, Water JJ, Aho J, Arnfast L, Bohr A, et al. (2016) Modifying release characteristics from 3D printed drug-eluting products. Eur J of Pharm Sci 90: 47-52.

22. Clark EA, Alexander MR, Irvine DJ, Roberts CJ, Wallace MJ, et al. (2017) 3D printing of tablets using inkjet with UV photo initiation. Int J of Pharm 529(1-2): 523: 530.

23. Chai X, Chai H, Wang X, Yang J, Li J, et al. (2017) Fused Deposition Modeling (FDM) 3D Printed Tablets for Intragastric Floating Delivery of Domperidone. Scientific Reports 7: 2829.

24. Genina N, Janßen EM, Breitenbach A, Breitkreutz J, Sandler N (2013) Evaluation of different substrates for inkjet printing of rasagiline mesylate. Eur J Pharm Biopharm 85(3): 1075-1083. 
25. Genina N, Boetker JP, Colombo S, Harmankaya N, Rantanem J, et al. (2017) Anti-tuberculosis drug combination for controlled oral delivery using 3D printed compartmental dosage forms: From drug product design to in vivo testing. J of Cont Release 268(28): 40-48.

26. Genina N, Hollander J, Jukarainen H, Makila E, Salonen J (2016) Ethylene vinyl acetate (EVA) as a new drug carrier for 3D printed medical drug delivery devices. Eur J of Pharm Sci 90: 53-63.

27. Gioumouxouzis CI, Katsamenis O, Bouropoulos N, Fatouros DG (2017) 3D printed oral solid dosage forms containing hydrochlorothiazide for controlled drug delivery. J of Drug Del Sci and Tech 40: 164-171.

28. Goyanes A, Det-Amornrat U, Wang J, Basit AW, Gaisford S (2016) 3D scanning and 3D printing as innovative technologies for fabricating personalized topical drug delivery systems. J of Cont Rel 234(28): 41-48.

29. Goyanes A, Martinez PR, Buanz A, Basit AW, Gaisford S. Effect of geometry on drug release from 3D printed tablets. Int J of Pharm 494(2): 657-663.

30. Hollander J, Genina N, Jukarainen H, Khajeheian M, Rosling (2016) 3D printed UV light cured poly dimethylsil oxane devices for drug delivery. Int J pharm 5173(17)31071-31072.

31. Sadia M, Arafat B, Ahmed W, Forbes RT, Ahlnan MA (2018) Channelled tablets: An innovative approach to accelerating drug release from 3D printed tablets. J Cont Rel 269: 355-363.

32. Solanki NG, Tahsin M, Shah AV, Serajuddin (2018) A.T.M. Formulation of 3D Printed Tablet for Rapid Drug Release by Fused Deposition Modeling: Screening Polymers for Drug Release, Drug-Polymer Miscibility and Printability. J Pharm Sci 107: 390-401.

33. Yi HG, Choi YJ, Kang KS, Hong JM, Pati RG, et al. (2016) A 3D-printed local drug delivery patch for pancreatic cancer growth suppression. J Cont Rel 238: 231-241.

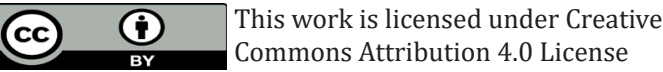

To Submit Your Article Click Here:

Submit Article

DOI: 10.32474/AOICS.2018.01.000109

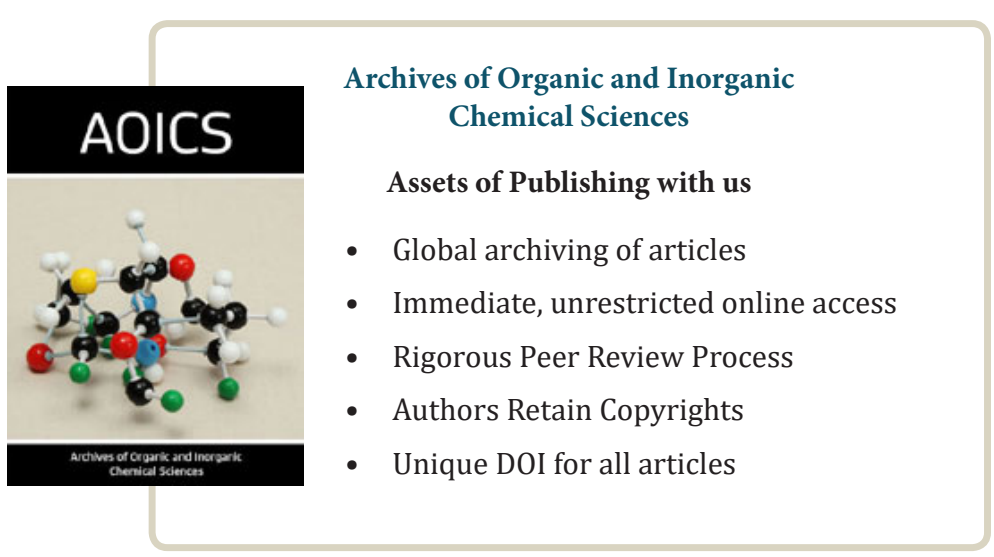

